\title{
GASTROPHYSICS: THE LENS OF PSYCHOLOGICAL AND SENSORY RESEARCH
}

\section{Prof. Charles Spence, Crossmodal Research Laboratory, Department of Experimental Psychology, University of Oxford}

The perfect meal may be something as simple as a picnic in a summer meadow or once in a lifetime trip to one of the world's top Michelin-starred restaurants. But a great eating experience depends on not just the food but far more on 'the everything else' that surrounds the meal such as the mood we are in through to the company we keep, the environment and the plating, plate ware, and cutlery [1-4].

The emerging body of research from the new field of gastrophysics (gastro from gastronomy and physics from psychophysics) is helping to isolate just how important these various factors are to our perception and enjoyment of food [3]. The pleasures of the table reside far more in the mind than we realize and perhaps even more in the mind than in the mouth. Gastrophysics is the new area of research that takes us away from three decades of the molecular gastronomy approach (science in the kitchen) to the neglected area of mental processes regarding the perception and enjoyment of food (science of the dinning).

Hence, the role of the senses is considered of critical importance in gastrophysics, including the appearance of food, the sound of food, forgotten flavor senses, the smell, the taste, the touch, the texture as well as all the other oral and sensory inputs that surround the food. Some of the most exciting recent examples of the dynamic interplay between chefs, designers, and sensory scientists give rise to exciting new immersive, experiential and most definitely multisensory, dining experiences including how taste is influenced by sight, by sound, by touch.

The recent interest in trying to understand eating experiences through the lens of psychological and sensory research is increasingly highlighting the fact that the pleasure and 
enjoyment of food does not depend solely on the edible elements laid out on the plate. Our food experiences are multisensory and integrated at perceptual and semantic levels [5-10]. Therefore, the atmosphere or the environment in which the food is consumed, visual and structural arrangement of the elements on the plate, the weight of utensils that we use to eat, color and material of cutlery made are considered to significantly affect the diner's perception of a dish and perceived taste and flavor of the food [5-10].

We have conducted a study in a realistic dining environment, in which two groups of diners were served the same three-course meal while the presentation of the starter (centred vs. offset plating), the type of cutlery, and the shape and colour of the plate on which that dessert served were varied [5]. The results revealed that the diners' appreciation of the food is affected by the presentation of the starter (centred vs. offset plating), the weight and type of the cutlery used to eat, the shape and colour of the plate in terms of liking, aesthetic value and willingness to pay for the food, supporting a growing body of gastrophysics research highlighting the importance of food-extrinsic factors in modulating the diner's opinion of the meal that they have been served [5] (Fig. 1).
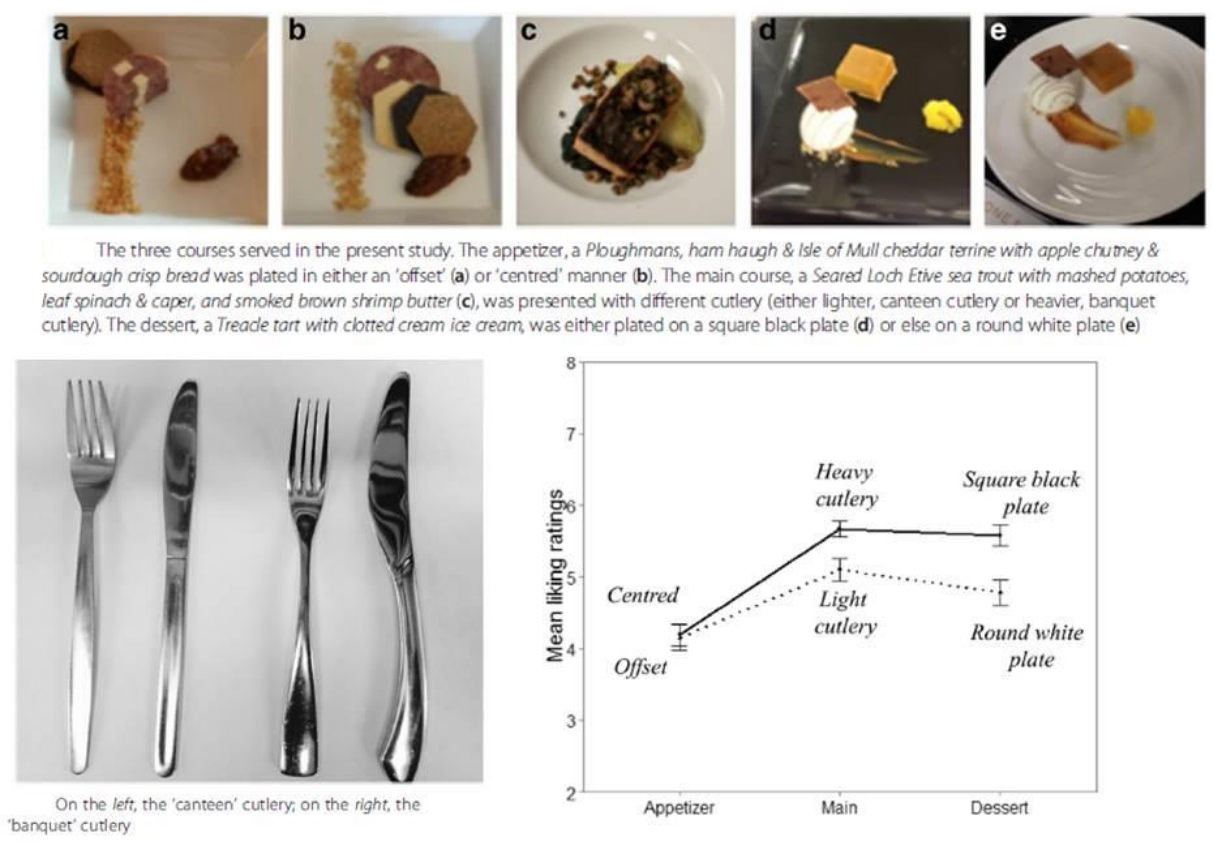

petizer, a Ploughmans, ham haugh \& isle of Mull cheddar terrine with apple chumey \& sourdough cisp bread was plated in either an 'offset' (a) or 'centred' manner (b). The main course, a Seared Loch Etive sea trout with mashed potatoes, leaf spinach \& caper, and smoked brown strimp butter (c), was presented with different cutlery (either lighter, canteen cutlery or heavier, banquet
cutlery). The dessert, a Treade tart with clotted cream ice cream, was either plated on a square black plate (d) or else on a round white plate (e)

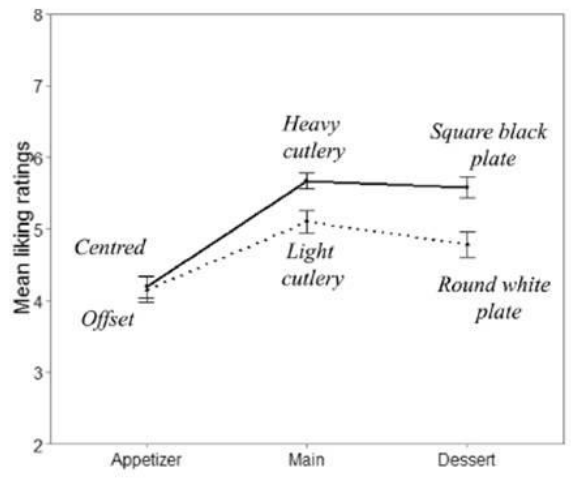

Figure 1. Factors affecting diners' appreciation of the food 
In another study, we have assessed whether placing the culinary elements of a dish in an artinspired manner would modify the diner's expectations and hence their experience of food using three different presentations of the dish [6]. One was simply plated (with all of the elements of the salad tossed together), another with the elements arranged to look like one of Kandinsky's paintings, and a third arrangement in which the elements were organized in a neat (but non-artistic) manner [6]. We have found that the Kandinsky-inspired plating was associated with being considered as more artistic, more complex, and more liked and being willing to pay more for before consumption, while higher tastiness ratings after consumption. These results support the idea that presenting food in an aesthetically pleasing manner can enhance the experience of a dish, and the use of artistic (visual) influences can enhance diner's expectations and subsequent experience of a dish [6] (Fig. 2).
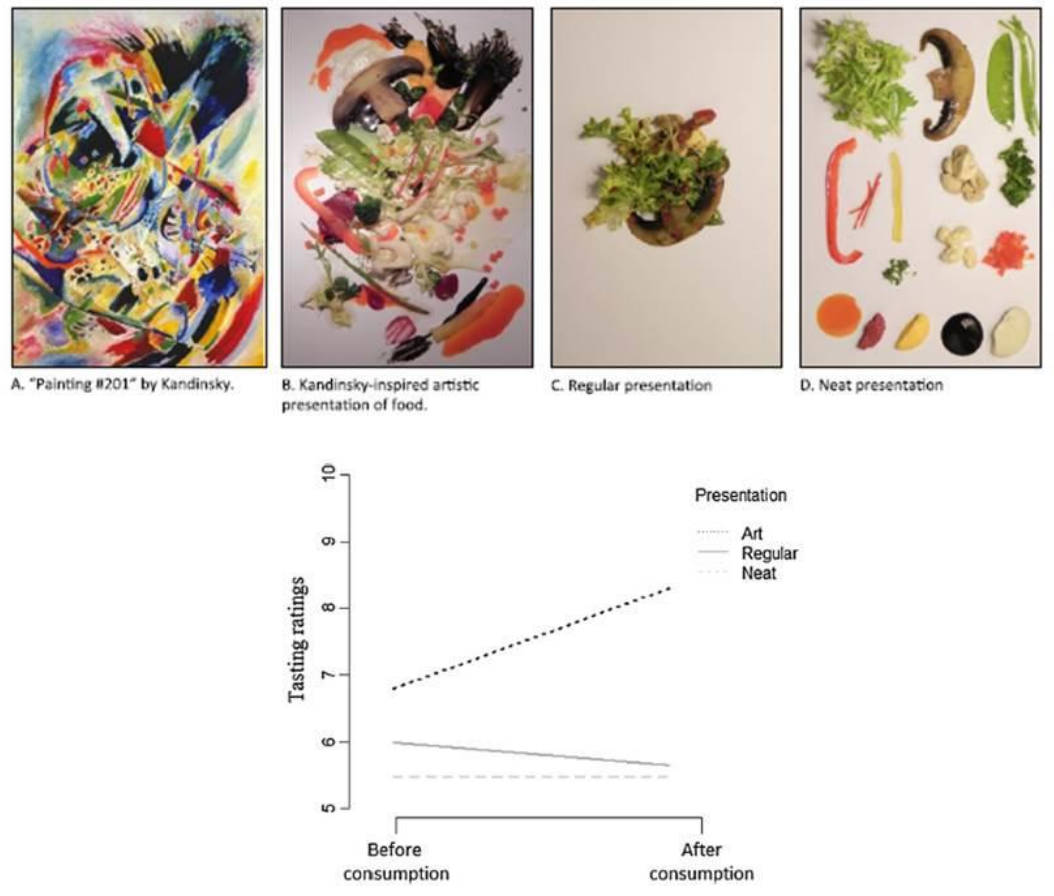

Figure 2. The impact of placing the culinary elements of a dish in an art-inspired manner on the diner's expectations and experience of food

In the hospital sector, data from Salisbury district hospital in the South of England showed that plate color really matters to patients with simply changing the colour from white to a high-contrast blue or red researchers reported a $30 \%$ increase in consumption, which is 
something of the utmost importance, as it may help to reduce the length of stay for these patients.

In addition, renaming the "Patagonian tooth fish" on the menu over the years as "Chilean Sea Bass" has increased sales by $1200 \%$ across North America, the UK, Australasia and beyond. Furthermore, given that predominant role of olfactory sensation in what we think we taste, designing cans, bottles and lids differently seems important to enhance the ability to autonasally sniff the aroma based on a gastrophysics. For the use of technology at the table, the idea of sonic seasoning is a really exciting area with documented existence of a cross-modal correspondence between sweet tastes and high pitched sounds and between bitter tastes and low-pitched sounds as well as other cross-modal correspondences between various parameters of musical composition and specific taste/flavor attributes [11-14].

In conclusion, gastrophysics is an exciting new area of science that shifts the focus from the food to the mind of the diner who is consuming the food. The search for the perfect meal can lead to interventions that may potentially help to tackle the growing obesity crisis, and may provide some intriguing ideas about how to get us all to shift to a rather more sustainable diet in the decades ahead.

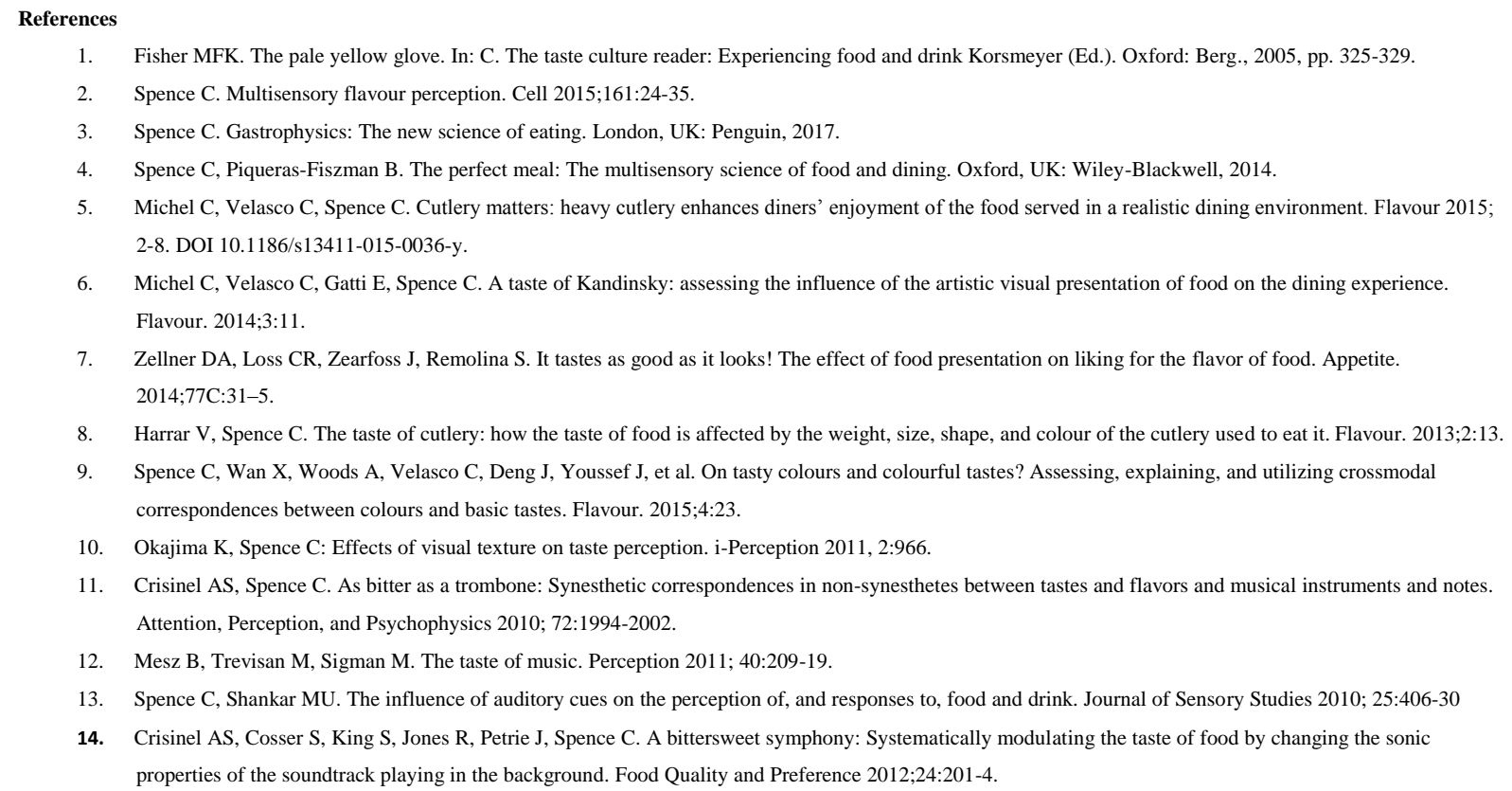

